\section{Tectonic, a novel regulator of the Hedgehog pathway required for both activation and inhibition}

\author{
Jeremy F. Reiter ${ }^{1,4}$ and William C. Skarnes ${ }^{2,3}$ \\ ${ }^{1}$ Developmental and Stem Cell Biology Program, and Diabetes \\ Center, University of California, San Francisco, California \\ 94143-0525, USA; ${ }^{2}$ Department of Molecular and Cell \\ Biology, University of California, \\ Berkeley, California 94720, USA
}

We report the identification of a novel protein that participates in Hedgehog-mediated patterning of the neural tube. This protein, named Tectonic, is the founding member of a previously undescribed family of evolutionarily conserved secreted and transmembrane proteins. During neural tube development, mouse Tectonic is required for formation of the most ventral cell types and for full Hedgehog (Hh) pathway activation. Epistasis analyses reveal that Tectonic modulates Hh signal transduction downstream of Smoothened (Smo) and Rab23. Interestingly, characterization of Tectonic Shh and Tectonic Smo double mutants indicates that Tectonic plays an additional role in repressing $\mathrm{Hh}$ pathway activity.

Supplemental material is available at http://www.genesdev.org.

Received August 9, 2005; revised version accepted November 2, 2005.

Hh signals are secreted proteins essential for normal development and tissue homeostasis. Misregulation of $\mathrm{Hh}$ signaling in humans can lead to congenital defects and cancers (McMahon et al. 2003). The most extensively studied function of the Hedgehog (Hh) family member Sonic hedgehog (Shh) is its role in the developing neural tube. There, Shh acts as a morphogen to direct the production of particular neuronal subtypes at defined dorsoventral positions (Jacob and Briscoe 2003). Shh mediates its effects by binding to its receptor, Patched (Ptch). Ptch, in the absence of Shh, represses the downstream signaling pathway by inhibiting the activity of Smoothened (Smo), a seven-transmembrane protein. Binding of Shh to Ptch relieves the repression of Smo, triggering events that culminate in the activation of transcription factors of the Gli family. How Hh signals are transduced is incompletely understood.

[Keywords: Shh; signal transduction; mouse development; neural patterning; open brain]

${ }^{3}$ Present address: Wellcome Trust Sanger Institute, Wellcome Trust Genome Campus, Hinxton, Cambridge, CB10 1SA, United Kingdom. ${ }^{4}$ Corresponding author.

E-MAIL jreiter@diabetes.ucsf.edu; FAX (415) 514-2346.

Article published online ahead of print. Article and publication date are at http://www.genesdev.org/cgi/doi/10.1101/gad.1363606.

\section{Results and Discussion}

Through a screen for genes encoding secreted and transmembrane proteins (Skarnes et al. 1995; Mitchell et al. 2001), we identified a novel gene which, because it is involved in a diverse range of developmental processes, we named Tectonic after the Greek word for builder. Conceptual translation of Tectonic indicates that it encodes a $63-\mathrm{kDa}$ protein with no recognized domains other than an N-terminal signal peptide. Genomic database searches identify two other mammalian Tectonic family members, Tect 2 and Tect 3 , which are $49 \%$ and $58 \%$ similar to Tectonic, respectively (Supplementary Fig. 1). The Drosophila genome contains a single Tectonic homolog. Thus, Tectonic is the founding member of an evolutionarily conserved family of proteins of undetermined function.

To assess whether Tectonic is secreted as predicted, we created a fusion between the putative Tectonic signal peptide and alkaline phosphatase. This fusion is robustly secreted by Cos 7 cells, indicating that the signal peptide is functional (Supplementary Fig. 2). Interestingly, fulllength Tectonic is not secreted by Cos 7 cells, suggesting that its secretion may be regulated.

Insertion of the gene trap vector in Tectonic occurs in the first of 12 introns (Fig. 1A). The resultant mutant allele encodes a fusion between the first 57 amino acids of Tectonic and a membrane-spanning ßgeo reporter (Mitchell et al. 2001). Given that no wild-type transcript is detectable in Tectonic mutants by RT-PCR and Northern blot analyses (Fig. 1B,C), and that transmembrane $\beta$ geo fusion proteins are retained in intracellular compartments (Skarnes et al. 1995), the Tectonic gene trap is likely to be a null allele.

During embryonic development, Tectonic is expressed in regions that participate in $\mathrm{Hh}$ signaling. Tectonic is first expressed during gastrulation stages in the ventral node (Fig. 1D,E). At embryonic day 9.5 (E9.5), Tectonic is expressed in the gut endoderm, limb buds, notochord, somites, neural tube and floorplate (Fig. 1F). Unlike regulators of Hh signaling such as Ptch and Hhip (Goodrich et al. 1996; Marigo and Tabin 1996; Chuang and McMahon 1999|, Tectonic is not a transcriptional target of $\mathrm{Hh}$ signaling (Supplementary Fig. 3B,C).

Tectonic mutants die between E13.5 and E16.5 and display holoprosencephaly (Fig. 1G), a defect associated with reduced Hh signaling (Chiang et al. 1996). Shh mediates induction of the floorplate, a histologically distinct cell population at the ventral midline of the neural tube. Like Shh mutants and Gli2 mutants (Chiang et al. 1996; Ding et al. 1998; Matise et al. 1998), Tectonic mutants fail to form floorplates and, instead, cells of neural morphology are present at the midline (Fig. 2A). Molecular analysis with the markers Shh and FoxA2 (Hnf $3 \beta$ ) confirms that Tectonic is required for floorplate formation (Figs. 2B, 3B). However, the notochord forms normally in Tectonic mutants as judged by Shh and Brachyury expression (Fig. 2B; Supplementary Fig. 3D). Thus, axial defects in Tectonic mutants are confined to the floorplate.

In addition to the floorplate, high levels of Hh signaling are required for the induction of the adjoining V3 interneurons (Litingtung and Chiang 2000; Wijgerde et 
A

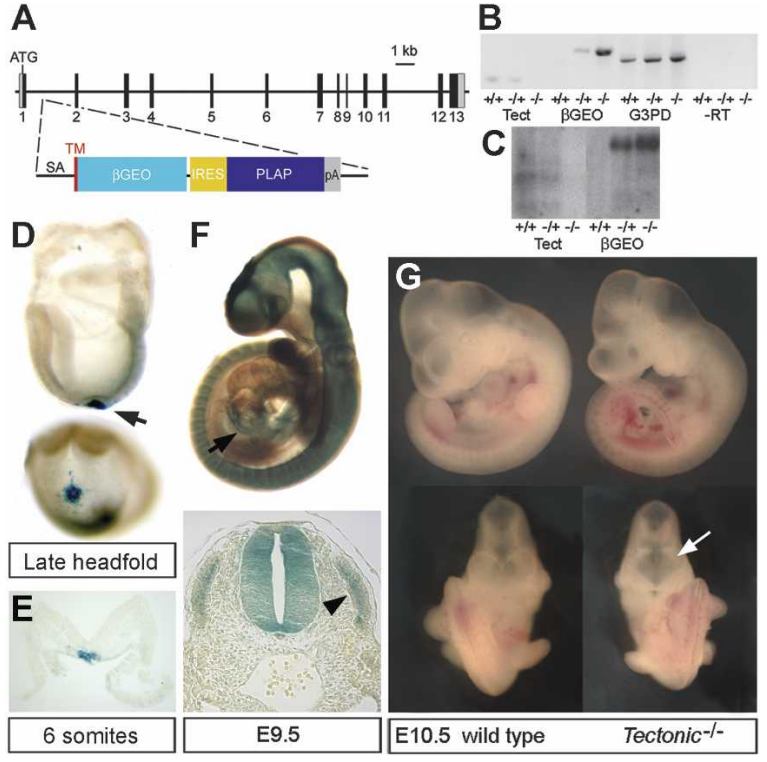

Figure 1. Tectonic is expressed in domains of Hh signaling, and is essential for embryonic development. (A) The mouse Tectonic gene is comprised of 13 exons on chromosome 5 . The gene trap consists of a strong splice acceptor (SA) followed by an ORF encoding a transmembrane domain (TM) and $\beta$ GEO. The gene trap also includes an IRES and PLAP coding sequence followed by a polyadenylation sequence (pA). (B) RT-PCR analysis of Tectonic gene expression in E11.5 wild-type, heterozygous, and homozygous mutant embryos. Primers are specific for the Tectonic coding sequence $3^{\prime}$ to the gene trap (Tect), the $\beta G E O$ transcript, and G3PD. Included is a -RT control using G3PD-specific primers. (C) Northern blot analysis of Tectonic and $\beta G E O$ expression in wild-type, heterozygous, and mutant embryos. $(D-F) \quad \beta$-Galactosidase staining of Tectonic heterozygotes. $(D)$ Lateral and distal views of late headfold stage embryos, demonstrating restricted Tectonic expression in the node (arrow). (E) Tectonic is expressed in the ventral epithelium of the node, as revealed in a transverse section through the node of a sixsomite stage embryo. $(F)$ At E9.5, Tectonic is expressed in the neural tube, gut epithelium (arrow), notochord, and somites (arrowhead), as seen both in whole-mount and transverse section. (G) E10.5 Tectonic mutants exhibit reduced telencephalon size and holoprosencephaly (arrow).

al. 2002). Analysis of neural tube patterning reveals that, like Shh, Tectonic is required for formation of the Sim1expressing V3 interneurons (Fig. 2C). Nkx2.2, a marker of the progenitors of the $\mathrm{V} 3$ interneurons (Briscoe et al. 1999), is also lost in Tectonic mutants (Fig. 3C), suggesting that these defects are not due to defects in neuronal maturation, but in their specification. Moreover, the Tectonic-dependent defects in ventral neural development are not limited to the V3 interneurons. Tectonic mutants also display a variable reduction in the number of Islet1/2-positive motor neurons (Fig. 3D). However, Tectonic is not required for the expression of $D b \times 1$ or Dbx2 (Fig. 2D; data not shown), indicating that Tectonic function is not essential for the development of more dorsal cell fates within the neural tube.

The loss of ventral neural markers in Tectonic mutants is accompanied by a ventral expansion of genes normally restricted to more dorsal domains. High levels of Hh signaling exclude expression of Irx 3 from the V3 and motor neuron progenitor (p3 and $\mathrm{pMN}$ ) domains (Briscoe et al. 2000). In Tectonic mutants, Irx3 expression expands to include all but a small number of ventral cells (Fig. 2E). Similarly, expression of Pax6, another fac- tor repressed by high Hh signaling (Ericson et al. 1997), is dramatically expanded in Tectonic mutants (Fig. 3B). Taken together, these changes in marker expression indicate that Tectonic is essential for the induction of the ventral-most cell types of the neural tube. These patterning defects are qualitatively similar to those caused by mutations in Shh or Gli2 (Chiang et al. 1996; Ding et al. 1998; Matise et al. 1998; Litingtung and Chiang 2000), suggesting that Tectonic participates in Hh signaling.

To test this hypothesis, we examined the expression of Gli1 and Ptch, two general Hh transcriptional targets. Significantly, Gli1 expression is reduced throughout Tectonic mutant embryos at E9.5 (Fig. 2F). In the developing neural tube of Tectonic mutants, expression of Gli1 and Ptch is similarly dramatically reduced (Fig. $2 \mathrm{G}, \mathrm{H})$. Hh signaling in the neural tube is antagonized by Bmp activity (Barth et al. 1999; Kawakami et al. 2005). Expression of Msx1, a readout of Bmp pathway activity in the dorsal neural tube (Liu et al. 2004), is normal in

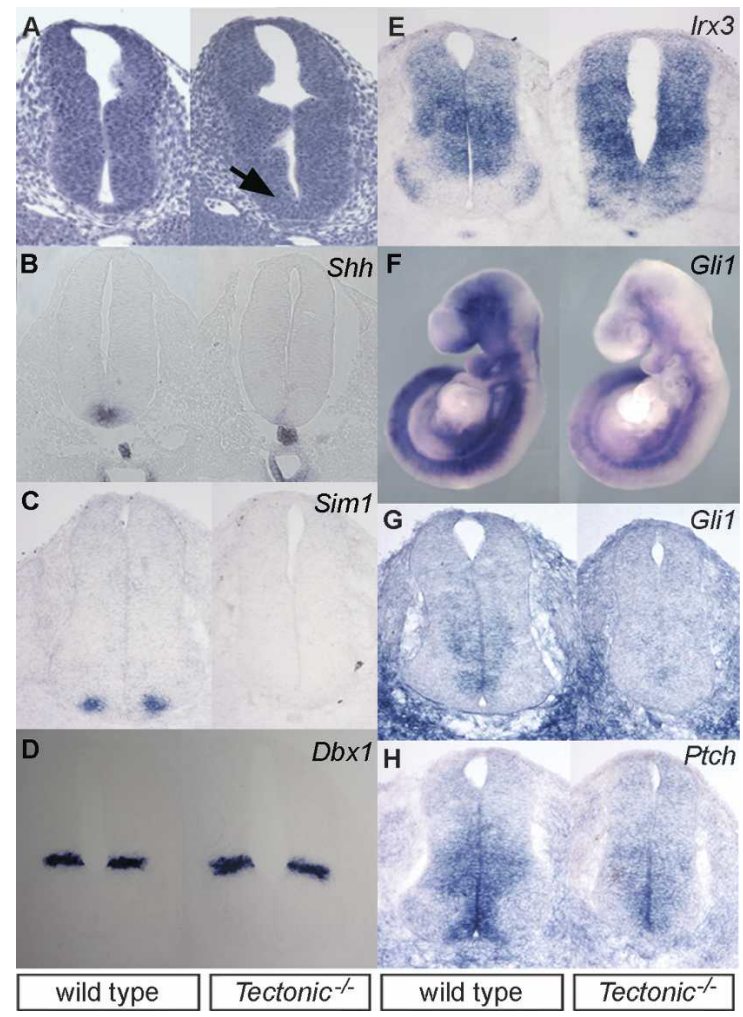

Figure 2. Tectonic is required for Hh-mediated patterning of the ventral neural tube. (A) Hematoxylin-and-eosin-stained transverse sections of E9.5 embryos. Tectonic mutants lack a histologically distinct floorplate (arrow). $(B-H)$ In situ hybridization of E9.5 wholemount embryos $(F)$, or transverse sections of E9.5 $(B)$ or E10.5 $(C-$ $E, G, H$ ) embryos. (B) Shh, a marker of the floorplate, is not expressed in the Tectonic mutant neural tube. However, Tectonic mutants express Shh normally in the notochord and gut epithelium. $(C)$ Similarly, Sim1, a marker of V3 interneurons, is not expressed in the Tectonic mutant neural tube. $(D)$ Expression of $D b \times 1$, a marker of V0 interneuron precursors, is expressed in Tectonic mutants. (E) Expression of Irx3, a gene normally expressed dorsal to the pMN domain, is expanded almost to the ventral midline of Tectonic mutants. (F) Gli1, a general transcriptional target of Hh signaling, is broadly diminished in Tectonic mutants. (G) Similarly, Gli1 expression is reduced in the neural tubes of Tectonic mutants. $(H)$ Ptch, another general Hh transcriptional target, is also down-regulated in the Tectonic mutant neural tube. 
Tectonic mutants (Supplementary Fig. 4), suggesting that Tectonic does not influence Hh signaling indirectly by altering Bmp activity. Together, these results argue that Tectonic acts in neural patterning by positively regulating the $\mathrm{Hh}$ pathway.

Conceptually, Tectonic could contribute to Hh signaling by participating in the creation of the $\mathrm{Hh}$ protein gradient or in the interpretation of that gradient. To distinguish between these two possibilities, we carried out epistasis experiments with Ptch mutants. If Tectonic acts in $\mathrm{Hh}$ processing, release or distribution, Ptch should be epistatic to Tectonic. However, if Tectonic acts in Hh signal transduction, Tectonic should be epistatic to Ptch. Ptch-dependent defects in embryonic turning and dorsal neural tube closure are ameliorated in Tectonic Ptch double mutants (Fig. 3A). Embryos lacking Ptch function show marked expansion of the ventral domains of the neural tube (Fig. 3B-D; Goodrich et al. 1997). Examination of the dorsoventral patterning of the neural tube of Tectonic Ptch double mutants reveals a loss of ventral neural fates indistinguishable from those of Tectonic single mutants (Fig. 3B-D).

Like Ptch, Rab23 is a negative regulator of the $\mathrm{Hh}$ pathway (Eggenschwiler et al. 2001; Huangfu et al. 2003). Embryos homozygous for the $o p b^{2}$ mutation in $R a b 23$ display a ventralized neural tube (Fig. 3E,F; Eggenschwiler and Anderson 2000). As with Ptch, embryos mutant for both Rab23 and Tectonic display neural tube patterning defects identical to those of Tectonic single mutants (Fig. 3E,F). Together, these results indicate that Tectonic is epistatic to both Ptch and Rab23. As Rab23 has been reported to act downstream of Smo (Huangfu et al. 2003), these data suggest that Tectonic modulates Hh transduction at a point downstream of Ptch, Smo, and Rab23.

To investigate whether the Tectonic-mediated effects on neural tube patterning reflect changes in Hh pathway activity, we assayed the expression of Gli1 in Tectonic Ptch double mutants (Fig. 3G). Loss of Ptch function

Figure 3. Tectonic is epistatic to Ptch and Rab23. (A) Lateral views of E9.5 littermates. Ptch mutants display a characteristic open neural tube and defective turning whereas normal turning is largely restored in Tectonic Ptch double mutants. $(B-D)$ Transverse sections of E9.5 embryos stained for expression of Pax6 in red and, in green, FoxA2 $(B), N k x 2.2(C)$, or Islet1/2 $(D)$. Nuclei are visualized with DAPI staining (blue). (B) Tectonic mutants lack floorplate expression of FoxA2 and show expanded Pax6 expression. Conversely, Ptch mutants display expanded FoxA2 expression and reduced Pax6 expression. Tectonic Ptch double mutants closely resemble Tectonic single mutants. (C) Tectonic mutants lack Nkx2.2 expression, a marker of the p3 domain, whereas Ptch mutants display expanded Nkx2.2 expression. Tectonic Ptch double mutants exhibit a loss of Nkx2.2 expression identical to that of Tectonic single mutants. $(D)$ Motor neuron expression of Islet $1 / 2$ is reduced in most $(n=4 / 5)$ Tectonic mutants, expanded in Ptch mutants, and reduced in Tectonic Ptch double mutants. $(E, F)$ Transverse sections of E10.5 embryos. (E) Similar to Ptch mutants, Rab23 mutants exhibit an expansion of FoxA2 (green) and a dorsal shift in expression of Olig2, a marker of motor neuron precursors (red). In contrast, Tectonic Rab23 double mutants resemble Tectonic mutants. $(F)$ Expression of the dorsal markers Pax3 and Pax6 is shifted dorsally in Rab23 mutants, but not in Tectonic Rab23 double mutants. (G) Gli1 in situ hybridization of transverse sections of E9.5 neural tubes. Whereas Gli1 is normally expressed in a dorsoventral gradient, in Ptch mutants, Gli1 is widely up-regulated and expressed ectopically in the dorsal neural tube. In Tectonic Ptch double mutants, Gli1 is expressed at a uniform low level throughout the dorsoventral extent of the neural tube. causes ectopic expression of high levels of Gli1 in the dorsal neural tube. In contrast, Tectonic Ptch double mutants display uniform low levels of Gli1 expression (Fig. 3G). These data confirm that Tectonic is essential for maximal activation of the $\mathrm{Hh}$ pathway. Furthermore, our results strongly suggest that Tectonic functions downstream of both Ptch and Rab23 in the Hh signal transduction pathway, and not in Hh production or release. Consistent with this conclusion, Shh protein is distributed in a dorsoventral gradient in Tectonic mutant neural tubes similar to that of wild-type neural tubes (Supplementary Fig. 5).

One of the most prominent defects displayed by Shh mutants is the severe reduction in forebrain development (Chiang et al. 1996). Strikingly, Tectonic Shh and
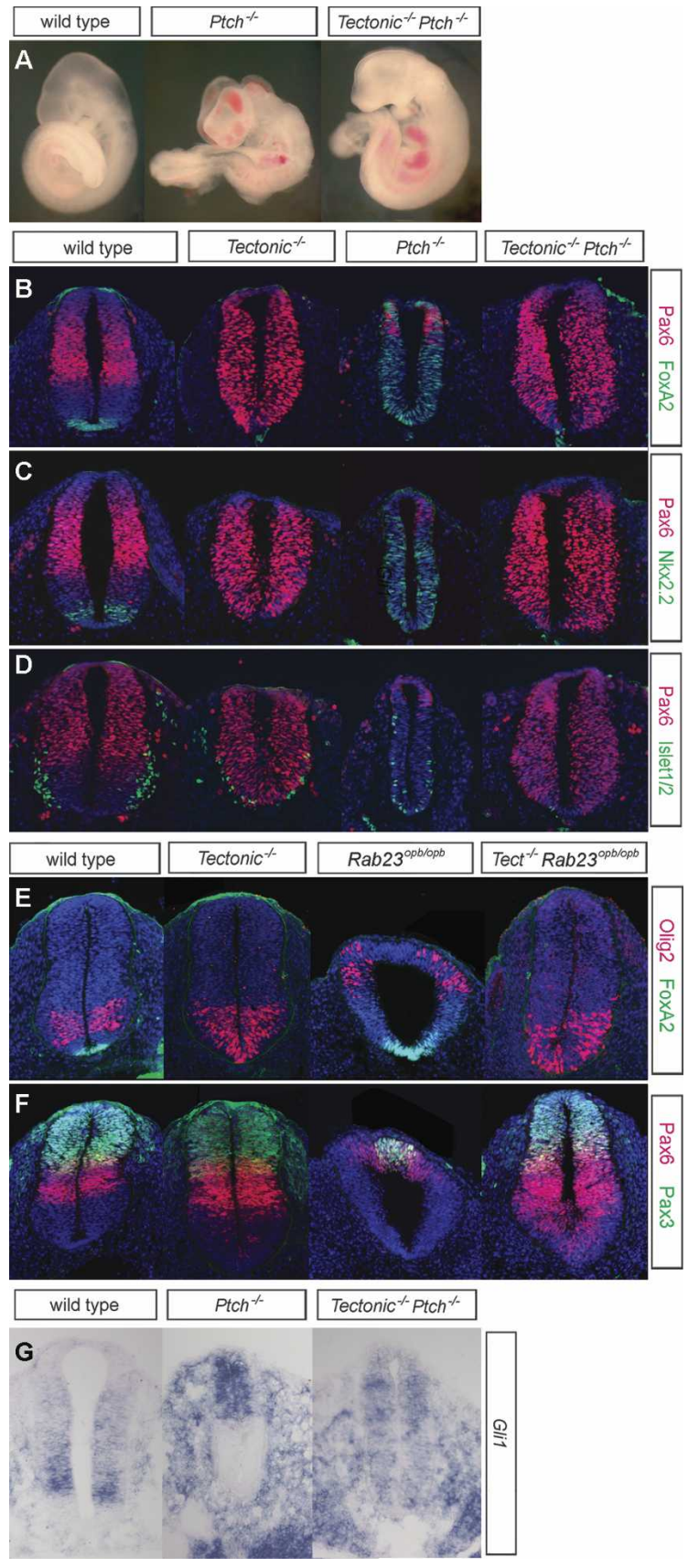
Tectonic Smo double mutants have considerably larger forebrains than do either Shh or Smo mutants (Fig. 4A; Supplementary Fig. 6). Although these results appear paradoxical given the reduced forebrains of Tectonic mutants, they suggest that there is a higher level of $\mathrm{Hh}$ activity in double mutants than in single mutants, implying that in addition to its role in pathway activation, Tectonic exerts a repressive effect on the pathway. To test whether this is the case, we examined neural tube

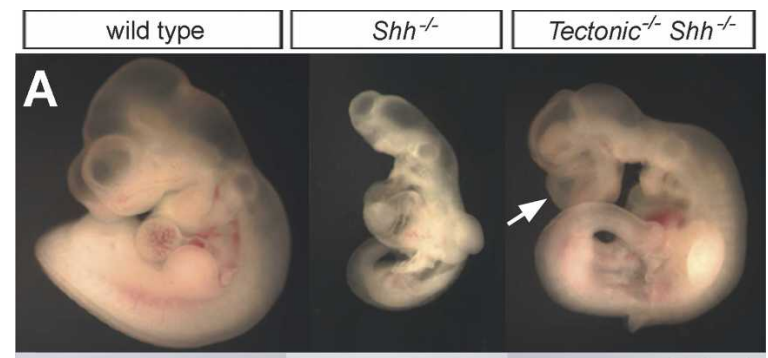

B

$D b \times 1$
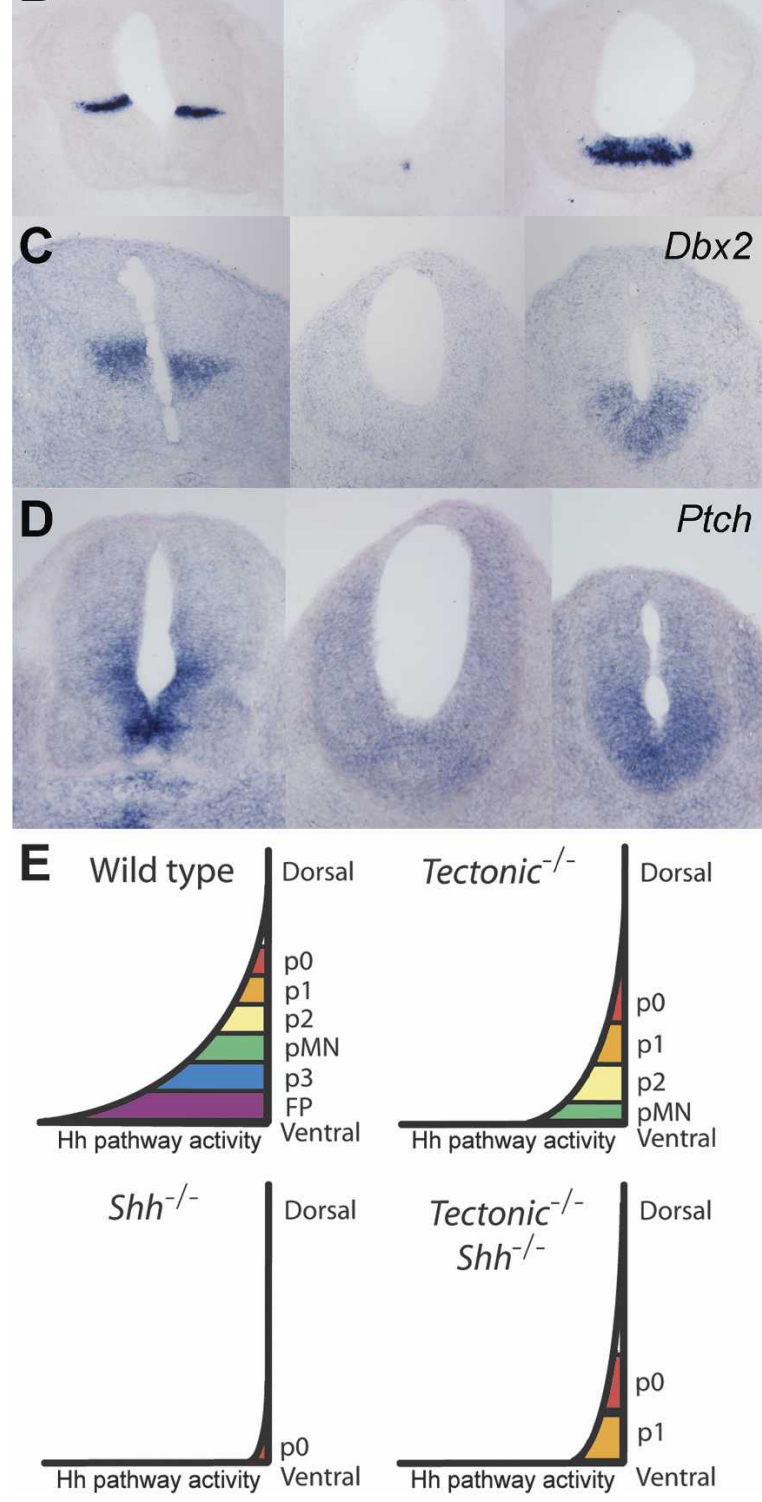

expression of $D b x 1$ and $D b x 2$, markers of the $\mathrm{p} 0$ and $\mathrm{p} 1$ precursors that are induced by low Hh levels (Wijgerde et al. 2002). If $\mathrm{p} 0$ and $\mathrm{p} 1$ formation in Tectonic mutants requires Shh activity, Tectonic Shh double mutants should show a reduction in $D b x 1$ and $D b x 2$ expression similar to that displayed by Shh mutants. However, our analysis reveals a dramatic increase in $D b \times 1$ - and $D b \times 2$ expressing cells in Tectonic Shh double mutants as compared to Shh single mutants (Fig. 4B,C). These surprising results demonstrate that $D b \times 1$ and $D b \times 2$ expression in Tectonic mutants is independent of Shh, and suggest that $\mathrm{Hh}$ pathway activity is higher in Tectonic Shh double mutants than in Shh mutants.

To assess whether increased $D b \times 1$ and $D b \times 2$ expression reflects increased $\mathrm{Hh}$ pathway activation, we examined Ptch expression in Tectonic Shh double mutants. We found that the abrogation of Ptch expression exhibited by Shh mutants is indeed partially alleviated by loss of Tectonic function (Fig. 4D), indicating that levels of Hh pathway activation are in fact higher in Tectonic Shh double mutants than in Shh mutants. The genetic interaction between Shh and Tectonic is similar to that observed between Shh and Gli3 (Litingtung and Chiang 2000) and suggest that Tectonic acts in a Shh-independent fashion to repress the Hh pathway. Taken with the forebrain data, these results reveal that Tectonic plays dual essential roles in both activating and inhibiting the Hh pathway in the anterior and posterior neural tube.

The loss of the activator function can be depicted as a rightward shift in the $\mathrm{Hh}$ pathway activity gradient of Tectonic mutants (Fig. 4E). Our additional finding that Tectonic inhibits Hh pathway activation in the absence of Shh can be represented graphically as a leftward shift in the Hh pathway activity gradient of Tectonic Shh double mutants relative to Shh mutants (Fig. 4E). This evidence that Tectonic functions in Hh signal transduction to fully activate the pathway in the presence of high Hh levels and to repress the pathway in the absence of Hh signals may reflect a combination of decreased function of both Gli activators and Gli repressors. In this regard, Tectonic joins a number of recently described regulators of $\mathrm{Hh}$ signal transduction including mouse IFT proteins (Huangfu et al. 2003; Liu et al. 2005) and

Figure 4. In addition to its role in mediating high levels of $\mathrm{Hh}$ signaling, Tectonic functions to repress low levels of Hh pathway activation. (A) Lateral view of E10.5 embryos. Shh mutants are onethird the size of littermates and show severely diminished forebrains. Tectonic Shh double mutants are larger than Shh single mutants and develop markedly larger telencephalons (arrow). (B-D) In situ hybridization of transverse sections of E10.5 embryos. $(B)$ In Shh mutants, $D b x 1$ expression, a marker of the p0 domain, is reduced to a very few cells at the ventral midline. Tectonic Shh double mutants exhibit increased $D b x 1$ expression relative to $S h h$ single mutants. (C) $D b x 2$, a marker of the p0 and p1 domains, is markedly reduced or not expressed in Shh mutants. In contrast, Tectonic Shh double mutants express $D b \times 2$ robustly at the ventral midline. (D) Tectonic Shh double mutants display higher levels of Ptch expression than do Shh single mutants. (E) Levels of Hh pathway activity within the developing ventral neural tube are translated into distinct fates, including floorplate (FP) and five neural precursor domains (p3-p0) at defined dorsoventral positions. In Tectonic mutants, neural fates that require the highest levels of $\mathrm{Hh}$ signaling are lost, represented as a rightward shift in the Hh pathway activity curve. Disruption of Shh function causes severe reduction of the p0 and p1 domains and loss of more ventral fates. In contrast, loss of both Shh and Tectonic function results in increased Hh pathway activity and restored $\mathrm{p} 0$ and $\mathrm{p} 1$ development, revealing an inhibitory role for Tectonic in the Hh pathway. 
zebrafish Iguana (Sekimizu et al. 2004; Wolff et al. 2004). Additionally, a Drosophila protein complex that includes Cos2 is similarly required for full pathway activation (Robbins et al. 1997; Sisson et al. 1997; Wang and Holmgren 2000; Wang et al. 2000; Lefers et al. 2001) and inhibition (Methot and Basler 2000; Stegman et al. 2000; Wang et al. 2000; Lefers et al. 2001). Tectonic is the first extracytosolic factor shown to act in this dual capacity.

Although the molecular mechanism by which Tectonic functions is not clear, our double mutant analyses suggest that it modulates $\mathrm{Hh}$ signal transduction at a point fairly downstream in the pathway. As Rab23 acts in the same region of the pathway and is thought to control vesicle transport, it will be interesting to assess whether it regulates the trafficking of Tectonic.

\section{Materials and methods}

Mouse strains

The mouse embryonic stem cell line KST296 carrying an insertion of the pGT1pfs secretory trap vector in the Tectonic gene was isolated as described in Mitchell et al. (2001). Tectonic F1 heterozygotes were backcrossed to $\mathrm{C} 57 \mathrm{Bl} / 6$ mice for six generations prior to intercrossing. Genotyping of Tectonic was performed using genomic PCR with a pair of wild-type-specific primers (5'-CGCCTCTTTAGCCCTCTGTT-3' and 5'-AGAACCTCCACGAGAGCAGA-3') and a mutant-allele-specific primer (5'-TCTAGGACAAGAGGGCGAGA-3'). Ptch, Rab23, Shh, and Smo embryos were genotyped as described (Chiang et al. 1996; Goodrich et al. 1997; Eggenschwiler et al. 2001; Zhang et al. 2001).

Secretion assays

Cos7 cells were transfected using Fugene6 (Roche) with APTag5 (GenHunter) or APTag5-TectSignal, a vector in which the SEAP signal sequence has been replaced with that of Tectonic. Alkaline phosphatase activity in the supernatant was chemiluminescently measured using the Phospha-Light Assay (Applied Biosystems) and a 20/20 ${ }^{\text {n }}$ luminometer (Turner BioSystems).

RT-PCR and Northern blot analyses

RT-PCR was performed using exon-spanning primers complementary to Tectonic cDNA $3^{\prime}$ to the gene trap insertion $\left(5^{\prime}\right.$-AATCCGCTGTTCC TTCCAC- $3^{\prime}$ and $5^{\prime}$-TGCGTCAGTGTGTGATTCAG- ${ }^{\prime}{ }^{\prime}$ ), to the $\beta G E O$ transcript $\left(5^{\prime}\right.$-CTTGGGTGGAGAGGCTATTC- ${ }^{\prime}{ }^{\prime}$ and $5^{\prime}$-AGGTGAG ATGACAGGAGATC-3'), and to G3PD (5'-GTGTTCCTACCCCCAAT GTG-3' and 5'-TGTGAGGGAGATGCTCAGTG-3'). Northern blots were hybridized to a Tectonic cDNA probe spanning exons 2-12 and a probe to $\beta g e o$.

Immunohistochemistry and in situ hybridization

$\mathrm{X}$-gal staining, in situ hybridization, and immunohistochemical staining were carried out using antibodies and protocols as previously described (Ericson et al. 1997; Briscoe et al. 1999, 2000; Takebayashi et al. 2000; Gritli-Linde et al. 2001) with the exception of rabbit $\alpha$-Pax6 antibody (Covance Research Products), which was used at 1:300. The $\alpha$-FoxA2, $\alpha$-Nkx2.2, $\alpha$-Islet1/2, $\alpha$-Msx1/2, and $\alpha$-Pax3 antibodies were obtained from the Developmental Studies Hybridoma Bank maintained by the University of Iowa under contract NO1-HD-7-3263 from the NICHD.

Gene analysis and accession numbers

Sequences of Tectonic family members were aligned using ClustalW and Boxshade 3.21. Domain analysis was performed with SignalP 3.0 and HMMTOP 2.0. Mouse Tectonic cDNA sequence, GenBank accession number DQ278867; human Tectonic cDNA sequence, GenBank accession number DQ278868; mouse Tect2 cDNA sequence, GenBank accession number DQ278869; human Tect2 cDNA sequence, GenBank accession number DQ278870; mouse Tect3 cDNA sequence, GenBank accession number DQ278871; human Tect3 cDNA sequence, GenBank accession number DQ278872; Drosophila dTectonic cDNA sequence, GenBank accession number DQ278873.

\section{Acknowledgments}

We are grateful to Debbie Pangilinan for expert mouse husbandry, to Andrew Norman for technical assistance, and to Pao-Tien Chuang and Andrew McMahon for the anti-Shh antibody Ab80. We thank Kevin Mitchell, Chulho Kang, and Marc Tessier-Lavigne for help generating the KST296 ES cell line and the Tectonic mice. This work was assisted by valuable conversations with Gail Martin, Pao-Tien Chuang, Didier Stainier, and Tom Kornberg. This research was supported by funding from the Chicago Community Trust and grants from the NICHD and NIMH. J.R. is a UCSF Fellow generously supported by the Sandler Foundation and a March of Dimes Basil O'Connor Award.

\section{References}

Barth, K.A., Kishimoto, Y., Rohr, K.B., Seydler, C., Schulte-Merker, S., and Wilson, S.W. 1999. Bmp activity establishes a gradient of positional information throughout the entire neural plate. Development 126: 4977-4987.

Briscoe, J., Sussel, L., Serup, P., Hartigan-O'Connor, D., Jessell, T.M., Rubenstein, J.L., and Ericson, J. 1999. Homeobox gene Nkx2.2 and specification of neuronal identity by graded Sonic hedgehog signalling. Nature 398: 622-627.

Briscoe, J., Pierani, A., Jessell, T.M., and Ericson, J. 2000. A homeodomain protein code specifies progenitor cell identity and neuronal fate in the ventral neural tube. Cell 101: 435-445.

Chiang, C., Litingtung, Y., Lee, E., Young, K.E., Corden, J.L., Westphal, H., and Beachy, P.A. 1996. Cyclopia and defective axial patterning in mice lacking Sonic hedgehog gene function. Nature 383: 407-413.

Chuang, P.T. and McMahon, A.P. 1999. Vertebrate Hedgehog signalling modulated by induction of a Hedgehog-binding protein. Nature 397: 617-621.

Ding, Q., Motoyama, J., Gasca, S., Mo, R., Sasaki, H., Rossant, J., and Hui, C.C. 1998. Diminished Sonic hedgehog signaling and lack of floor plate differentiation in Gli2 mutant mice. Development 125: 2533 2543.

Eggenschwiler, J.T. and Anderson, K.V. 2000. Dorsal and lateral fates in the mouse neural tube require the cell-autonomous activity of the open brain gene. Dev. Biol. 227: 648-660.

Eggenschwiler, J.T., Espinoza, E., and Anderson, K.V. 2001. Rab23 is an essential negative regulator of the mouse Sonic hedgehog signalling pathway. Nature 412: 194-198.

Ericson, J., Rashbass, P., Schedl, A., Brenner-Morton, S., Kawakami, A., van Heyningen, V., Jessell, T.M., and Briscoe, J. 1997. Pax6 controls progenitor cell identity and neuronal fate in response to graded Shh signaling. Cell 90: 169-180.

Goodrich, L.V., Johnson, R.L., Milenkovic, L., McMahon, J.A., and Scott, M.P. 1996. Conservation of the hedgehog/patched signaling pathway from flies to mice: Induction of a mouse patched gene by Hedgehog. Genes \& Dev. 10: 301-312.

Goodrich, L.V., Milenkovic, L., Higgins, K.M., and Scott, M.P. 1997. Altered neural cell fates and medulloblastoma in mouse patched mutants. Science 277: 1109-1113.

Gritli-Linde, A., Lewis, P., McMahon, A.P., and Linde, A. 2001. The whereabouts of a morphogen: Direct evidence for short- and graded long-range activity of hedgehog signaling peptides. Dev. Biol. 236: 364-386.

Huangfu, D., Liu, A., Rakeman, A.S., Murcia, N.S., Niswander, L., and Anderson, K.V. 2003. Hedgehog signalling in the mouse requires intraflagellar transport proteins. Nature 426: 83-87.

Jacob, J. and Briscoe, J. 2003. Gli proteins and the control of spinal-cord patterning. EMBO Rep. 4: 761-765.

Kawakami, A., Nojima, Y., Toyoda, A., Takahoko, M., Satoh, M., Tanaka, H., Wada, H., Masai, I., Terasaki, H., Sakaki, Y., et al. 2005. The zebrafish-secreted matrix protein you/scube2 is implicated in long-range regulation of hedgehog signaling. Curr. Biol. 15: 480-488.

Lefers, M.A., Wang, Q.T., and Holmgren, R.A. 2001. Genetic dissection of the Drosophila Cubitus interruptus signaling complex. Dev. Biol. 236: 411-420.

Litingtung, Y. and Chiang, C. 2000. Specification of ventral neuron types is mediated by an antagonistic interaction between Shh and Gli3. Nat. Neurosci. 3: 979-985.

Liu, Y., Helms, A.W., and Johnson, J.E. 2004. Distinct activities of Msx1 
and Msx3 in dorsal neural tube development. Development 131: $1017-1028$.

Liu, A., Wang, B., and Niswander, L.A. 2005. Mouse intraflagellar transport proteins regulate both the activator and repressor functions of Gli transcription factors. Development 132: 3103-3111.

Marigo, V. and Tabin, C.J. 1996. Regulation of patched by sonic hedgehog in the developing neural tube. Proc. Natl. Acad. Sci. 93: 9346-9351.

Matise, M.P., Epstein, D.J., Park, H.L., Platt, K.A., and Joyner, A.L. 1998. Gli2 is required for induction of floor plate and adjacent cells, but not most ventral neurons in the mouse central nervous system. Development 125: 2759-2770.

McMahon, A.P., Ingham, P.W., and Tabin, C.J. 2003. Developmental roles and clinical significance of hedgehog signaling. Curr. Top. Dev. Biol. 53: 1-114.

Methot, N. and Basler, K. 2000. Suppressor of fused opposes hedgehog signal transduction by impeding nuclear accumulation of the activator form of Cubitus interruptus. Development 127: 4001-4010.

Mitchell, K.J., Pinson, K.I., Kelly, O.G., Brennan, J., Zupicich, J., Scherz, P., Leighton, P.A., Goodrich, L.V., Lu, X., Avery, B.J., et al. 2001. Functional analysis of secreted and transmembrane proteins critical to mouse development. Nat. Genet. 28: 241-249.

Robbins, D.J., Nybakken, K.E., Kobayashi, R., Sisson, J.C., Bishop, J.M., and Therond, P.P. 1997. Hedgehog elicits signal transduction by means of a large complex containing the kinesin-related protein costal2. Cell 90: 225-234.

Sekimizu, K., Nishioka, N., Sasaki, H., Takeda, H., Karlstrom, R.O., and Kawakami, A. 2004. The zebrafish iguana locus encodes Dzip1, a novel zinc-finger protein required for proper regulation of Hedgehog signaling. Development 131: 2521-2532.

Sisson, J.C., Ho, K.S., Suyama, K., and Scott, M.P. 1997. Costal2, a novel kinesin-related protein in the Hedgehog signaling pathway. Cell 90: $235-245$.

Skarnes, W.C., Moss, J.E., Hurtley, S.M., and Beddington, R.S. 1995. Capturing genes encoding membrane and secreted proteins important for mouse development. Proc. Natl. Acad. Sci. 92: 6592-6596.

Stegman, M.A., Vallance, J.E., Elangovan, G., Sosinski, J., Cheng, Y., and Robbins, D.J. 2000. Identification of a tetrameric hedgehog signaling complex. J. Biol. Chem. 275: 21809-21812.

Takebayashi, H., Yoshida, S., Sugimori, M., Kosako, H., Kominami, R., Nakafuku, M., and Nabeshima, Y. 2000. Dynamic expression of basic helix-loop-helix Olig family members: Implication of Olig2 in neuron and oligodendrocyte differentiation and identification of a new member, Olig3. Mech. Dev. 99: 143-148.

Wang, Q.T. and Holmgren, R.A. 2000. Nuclear import of cubitus interruptus is regulated by hedgehog via a mechanism distinct from $\mathrm{Ci}$ stabilization and Ci activation. Development 127: 3131-3139.

Wang, G., Amanai, K., Wang, B., and Jiang, J. 2000. Interactions with Costal2 and suppressor of fused regulate nuclear translocation and activity of cubitus interruptus. Genes \& Dev. 14: 2893-2905.

Wijgerde, M., McMahon, J.A., Rule, M., and McMahon, A.P. 2002. A direct requirement for Hedgehog signaling for normal specification of all ventral progenitor domains in the presumptive mammalian spinal cord. Genes \& Dev. 16: 2849-2864.

Wolff, C., Roy, S., Lewis, K.E., Schauerte, H., Joerg-Rauch, G., Kirn, A., Weiler, C., Geisler, R., Haffter, P., and Ingham, P.W. 2004. iguana encodes a novel zinc-finger protein with coiled-coil domains essential for Hedgehog signal transduction in the zebrafish embryo. Genes \& Dev. 18: 1565-1576.

Zhang, X.M., Ramalho-Santos, M., and McMahon, A.P. 2001. Smoothened mutants reveal redundant roles for Shh and thh signaling including regulation of $\mathrm{L} / \mathrm{R}$ symmetry by the mouse node. Cell 106: 781-792. 


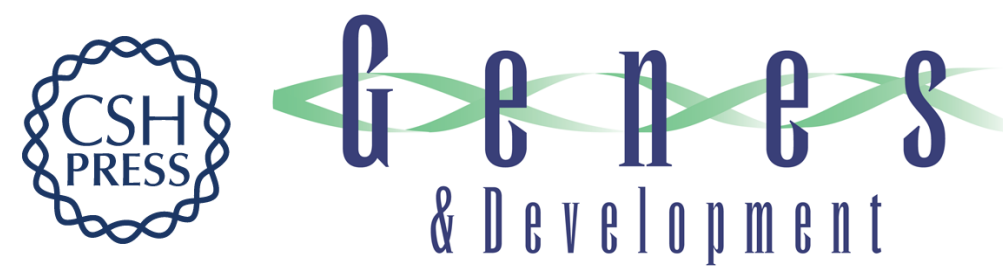

\section{Tectonic, a novel regulator of the Hedgehog pathway required for both activation and inhibition}

Jeremy F. Reiter and William C. Skarnes

Genes Dev. 2006, 20:

Access the most recent version at doi:10.1101/gad.1363606

Supplemental http://genesdev.cshlp.org/content/suppl/2005/12/20/gad.1363606.DC1
Material

References This article cites 35 articles, 16 of which can be accessed free at:

http://genesdev.cshlp.org/content/20/1/22.full.html\#ref-list-1

License

Email Alerting Receive free email alerts when new articles cite this article - sign up in the box at the top

Service right corner of the article or click here.

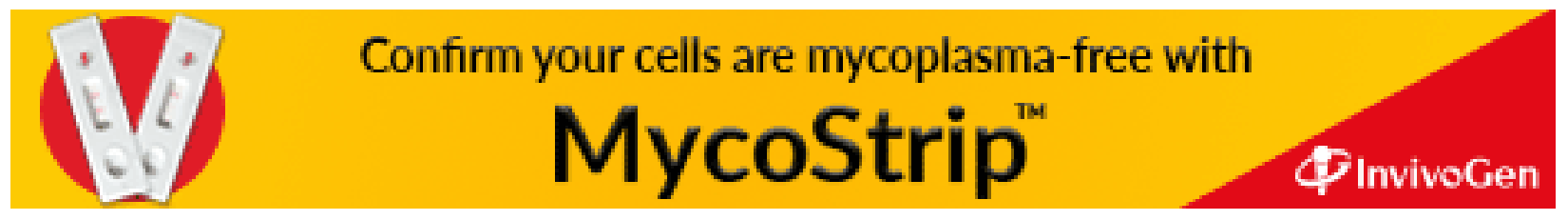

